\title{
Influence of relative humidity on the carbonation of calcium hydroxide nanoparticles and the formation of calcium carbonate polymorphs
}

P. López-Arce ${ }^{\mathrm{a}}$, L.S. Gómez-Villalba ${ }^{\mathrm{a}}$, S. Martínez-Ramirez ${ }^{\mathrm{b}, \mathrm{c}}$, M. Álvarez de Buergo ${ }^{\mathrm{a}}, \mathrm{C}$. Domingo $^{\text {c }}$, R. Fort ${ }^{\mathrm{a}}$

${ }^{a}$ Grupo de Petrología Aplicada a la Conservación del Patrimonio, Instituto de Geología Económica (CSIC-UCM), José Antonio Nováis 2, 28040, Madrid, Spain

${ }^{\mathrm{b}}$ Instituto de Ciencias de la Construcción (CSIC), C/Serrano Galvache 4, 28033, Madrid, Spain

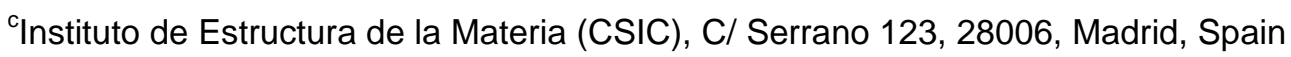

$\mathrm{Ca}(\mathrm{OH})_{2}$ nanoparticles dispersed in isopropyl alcohol were exposed under different relative humidities $(\mathrm{RH})$ during 7, 14, 21 and 28 days. Higher $\mathrm{RH}(75 \%-90 \% \mathrm{RH})$ gives rise to a faster carbonation (amorphous $\mathrm{CaCO}_{3}, \mathrm{CaCO}_{3} \cdot \mathrm{H}_{2} \mathrm{O}$, calcite, aragonite and vaterite) and larger particles sizes compared to lower $\mathrm{RH}(33 \%-54 \% \mathrm{RH})$ that gives rise only to portlandite $\left(\mathrm{Ca}(\mathrm{OH})_{2}\right)$ and vaterite with smaller particle sizes.
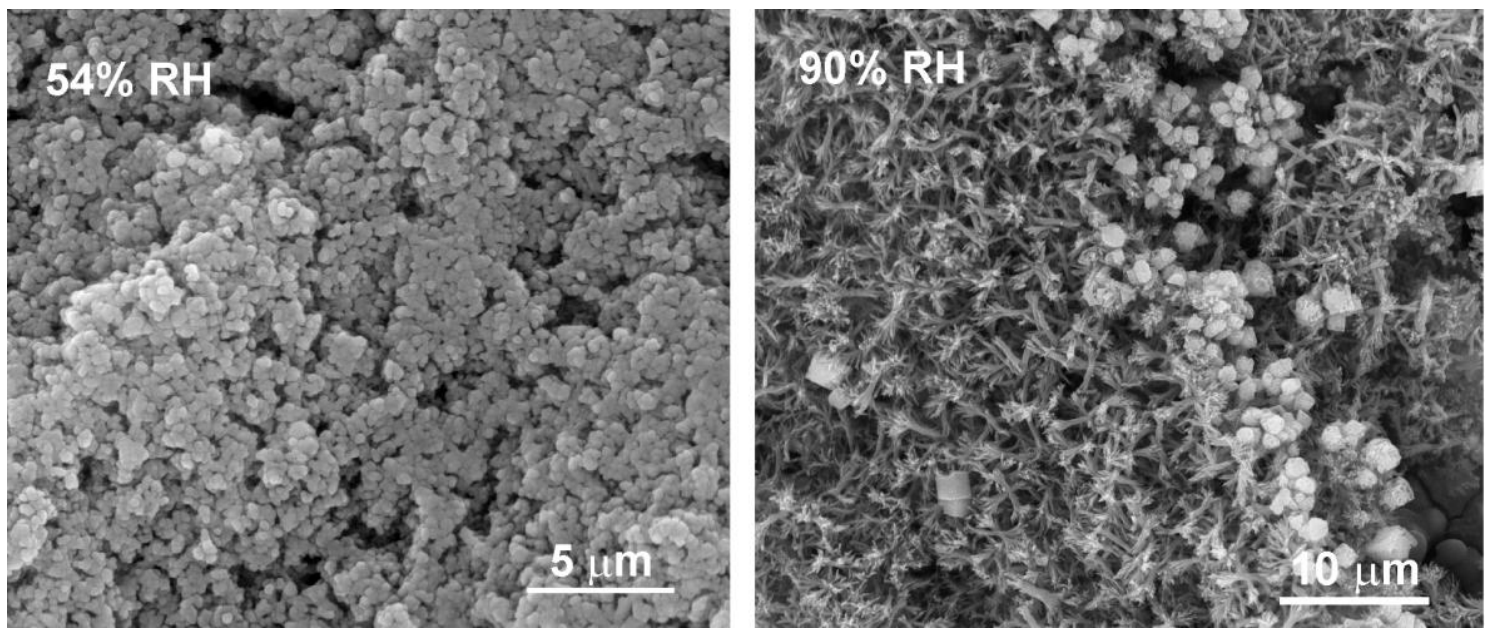
A consolidating product based on nanoparticles of slaked lime $\left(\mathrm{Ca}(\mathrm{OH})_{2}\right)$ dispersed in isopropyl alcohol was exposed under different relative humidities $(\mathrm{RH}), 33 \%, 54 \%, 75 \%$ and $90 \%$ during 7, 14, 21 and 28 days. The characterization of the calcium hydroxide nanoparticles and the formed calcium carbonate polymorphs has been performed by Micro-Raman spectroscopy, Transmission Electron Microscopy (TEM) and Environmental Scanning Electron Microscopy (ESEM) with Energy Dispersive X-ray Spectroscopy (EDS) and X-ray Diffraction (XRD). Precipitation and transformation of calcium carbonate polymorphs strongly depends on the relative humidity $(\mathrm{RH})$. Higher $\mathrm{RH}(75 \%-90 \% \mathrm{RH})$ gives rise to amorphous calcium carbonate and monohydrocalcite, calcite, aragonite and vaterite, faster carbonation and larger particles sizes compared to lower $\mathrm{RH}(33 \%-54 \% \mathrm{RH})$ that gives rise only to portlandite and vaterite, slower carbonation and smaller particle sizes. 


\title{
Influence of relative humidity on the carbonation of calcium hydroxide nanoparticles and the formation of calcium carbonate polymorphs
}

\author{
P. López-Arce ${ }^{a}$, L.S. Gómez-Villalba ${ }^{a}$, S. Martínez-Ramirez ${ }^{\mathrm{b}, \mathrm{c}}$, M. Álvarez de Buergo ${ }^{\mathrm{a}}, \mathrm{C}$. \\ Domingo ${ }^{c}$, R. Fort ${ }^{\mathrm{a}}$ \\ ${ }^{a}$ Grupo de Petrología Aplicada a la Conservación del Patrimonio, Instituto de Geología \\ Económica (CSIC-UCM), José Antonio Nováis 2, 28040, Madrid, Spain \\ ${ }^{\mathrm{b}}$ Instituto de Ciencias de la Construcción (CSIC), C/Serrano Galvache 4, 28033, Madrid, Spain

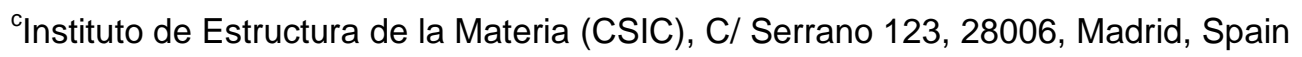

\section{Abstract}

A consolidating product based on nanoparticles of slaked lime $\left(\mathrm{Ca}(\mathrm{OH})_{2}\right)$ dispersed in isopropyl alcohol was exposed under different relative humidities $(\mathrm{RH}), 33 \%, 54 \%, 75 \%$ and $90 \%$ during 7, 14, 21 and 28 days. The characterization of the calcium hydroxide nanoparticles and the formed calcium carbonate polymorphs has been performed by Micro-Raman spectroscopy, Transmission Electron Microscopy (TEM) and Environmental Scanning Electron Microscopy (ESEM) with Energy Dispersive X-ray Spectroscopy (EDS) and X-ray Diffraction (XRD). Precipitation and transformation of calcium carbonate polymorphs strongly depends on the relative humidity $(\mathrm{RH})$. Higher $\mathrm{RH}(75 \%-90 \% \mathrm{RH})$ gives rise to amorphous calcium carbonate and monohydrocalcite, calcite, aragonite and vaterite, faster carbonation and larger particles sizes compared to lower $\mathrm{RH}(33 \%-54 \% \mathrm{RH})$ that gives rise only to portlandite and vaterite, slower carbonation and smaller particle sizes.

Keywords: Nanoparticles; calcium hydroxide; calcium carbonate polymorphs; relative humidity; carbonation. 


\section{Introduction}

Calcium hydroxide $\left(\mathrm{Ca}(\mathrm{OH})_{2}\right)$ is an important chemical with numerous chemical, industrial, environmental and architectural applications; especially in architecture and decorative arts it has been traditionally used as a primary material. ${ }^{1-3}$ The high reactivity and superior rheological properties of $\mathrm{Ca}(\mathrm{OH})_{2}$, both connected with a small particle size, are of paramount importance. ${ }^{3}$

Studies on the transformation mechanism of calcium carbonate $\left(\mathrm{CaCO}_{3}\right)$ are important to obtain a fundamental understanding on the formation of limestone. ${ }^{4}$ Carbonation is a factor of major importance in building materials such as cement, concrete and lime mortars. ${ }^{5}$ In the field of building and heritage conservation, carbonation is a major requirement when using $\mathrm{Ca}(\mathrm{OH})_{2}$ to consolidate and strengthen decayed carbonate stones, based on the fact of similar composition and suitability. Currently, carbonation method is the preferred one to obtain carbonates, in terms of environment preservation and the effective use of mineral resources. ${ }^{6}$ Lately, with the nanotechnology and nanomaterials boom, some attempts have been done towards creating $\mathrm{Ca}(\mathrm{OH})_{2}$ nanoparticles to be used as consolidants, in the same way as recent attempts to consolidate decayed granites with silica nanoparticles. ${ }^{7}$ The variables that play a role in the carbonation of these $\mathrm{Ca}(\mathrm{OH})_{2}$ nanoparticles (by themselves, but especially once they are applied to the stone), and the resulting mineral phases, with the existing $\mathrm{CaCO}_{3}$ polymorphs, is essential for the final properties of the consolidating product and, thus, for the success of the stone consolidation process. The use of $\mathrm{Ca}(\mathrm{OH})_{2}$ nanoparticles is funded by the fact that the specific surface area of a solid increases exponentially with the decrease of its volume, having the nanoparticles a much superior surface area available to react, and a better ability to penetrate in the stone pores net. ${ }^{8}$

The control of crystal shape and texture of the obtained product $\left(\mathrm{CaCO}_{3}\right)$ is important to the industrial and biological uses of these materials. ${ }^{9}$ However, to control the phases and the morphologies of $\mathrm{CaCO}_{3}$ in order to meet the demands in practical applications is still not well known. There are at least six different phases of calcium carbonate: three anhydrous crystalline polymorphs (calcite, aragonite and vaterite) and three hydrated forms (crystalline monohydrate (monohydrocalcite), crystalline hexahydrate (ikaite, $\left.\mathrm{CaCO}_{3} \cdot 6 \mathrm{H}_{2} \mathrm{O}\right)$ ) and an amorphous calcium carbonate hydrate..$^{10,11}$ The physical properties of the crystallized product depend largely on the percentage of each polymorph present. ${ }^{12}$ 
There are known factors and conditions that control the precipitation of these polymorphs: $\mathrm{pH}^{4}$, temperature, ${ }^{13-18}$ supersaturation, ${ }^{9,19,20}$, conductivity $^{21}$ or impurities and additives. ${ }^{10,12,22,23}$ However, the references on the influence of relative humidity on the precipitation and crystal habits of the different calcium carbonates polymorphs are very scarce. In this sense, Dheilly et al., ${ }^{24}$ when speaking of $\mathrm{Ca}(\mathrm{OH})_{2}$ storage, state that high relative humidity conditions with low level of $\mathrm{CO}_{2}$ and temperature $10^{\circ} \mathrm{C}$, favors carbonation, recommending a storage $\mathrm{RH}$ below $30 \%$ at a temperature between $20-30^{\circ} \mathrm{C}$ to prevent carbonation. ${ }^{25} \mathrm{~A}$ humid atmosphere seems to act upon the lime in accordance with the following three sequential steps: i) physical adsorption of the water held within the atmospheric humidity at the $\mathrm{Ca}(\mathrm{OH})_{2}$ grains' surface; ii) this water then allows the $\mathrm{Ca}(\mathrm{OH})_{2}$ to dissolve into $\mathrm{Ca}^{2+}$ and $\mathrm{OH}^{-}$ions. In addition, the dissolution of $\mathrm{CO}_{2}$ under these basic $\mathrm{pH}$ conditions $(\mathrm{pH} 10)$, yields $\mathrm{CO}_{3}^{-2}$ ions; iii) these two dissolution steps contribute to the precipitation of calcium carbonate. ${ }^{24}$ Research carried out by El-Turki et al., ${ }^{26}$ on lime pastes has shown that lime pastes exposed to $97 \% \mathrm{RH}$ resulted in a higher carbonation rate and complete carbonation compared to pastes exposed to $65 \% \mathrm{RH}$, where a small amount of calcium hydroxide was detected. When assessing the effectiveness of a consolidating product, it is essential to determine the optimum humidity conditions for consolidating porous carbonate stones from historical mural paintings, sculptures or buildings. Previous studies have shown that high relative humidity conditions $(75 \% \mathrm{RH})$ favors the consolidation process of dolostone,${ }^{27}$ even although consolidation process both in a dry and a humid environment improves the physical and hydric properties of carbonate stone specimens. Raman spectroscopy has recently proved to be a reliable technique that not only identifies carbonates of calcite structure, ${ }^{28}$ but the $\mathrm{CaCO}_{3}$ polymorphs, ${ }^{5,29,30}$ as it provides excellent fingerprint spectra specific to each crystal structure. There have been some attempts to quantify mixtures containing the three anhydrous polymorphs (calcite, aragonite and vaterite) with successful application of RS and X-Ray diffraction (XRD) on mixture of the calcium carbonate polymorphs. ${ }^{30,31}$ Moreover, Raman spectroscopy allows the detection of hydrated amorphous and crystalline phases which are considered as precursors for the anhydrous $\mathrm{CaCO}_{3}$ polymorphs. $^{32,33}$

Confocal Raman Imaging and Micro-Raman spectroscopy can be used to quantify the calcium carbonate polymorphs formed at different depths in lime mortar or carbonates stone in a non 
destructive way; ${ }^{5}$ both Raman based techniques combine the properties of traditional vibrational spectroscopy, with the additional advantages afforded by a much smaller analysis spot than in conventional Raman techniques. Transmission Electron Microscopy (TEM) is also a very useful complementary technique, which together with the electron diffraction allows identifying crystalline phases and their morphological characteristics, with a higher precision compared to other analytical techniques.

The aim of this research is to asses the influence of relative humidity as a condition that affects the carbonation of calcium hydroxide nanoparticles and the precipitation and transformation of the different calcium carbonate polymorphs.

\section{Experimental Section}

\subsection{Materials and sample preparation}

The nanometric calcium hydroxide dispersion used in this study was a commercial product: Nanorestore $\AA^{\circledR}$ developed at the University of Florence (CSGI Consortium) ${ }^{34}$ It is based on a colloidal suspension of nanoparticles of slaked lime dispersed in isopropyl alcohol. The concentration of calcium hydroxide nanoparticles is $5 \mathrm{~g} / \mathrm{l}$. This product with no dilution was deposited inside two closed desiccators used as climatic chambers at $20^{\circ} \mathrm{C}$ and at $33 \%, 54 \%$, $75 \%$ and $90 \%$ relative humidity $(\mathrm{RH})$ during different consolidation times, 7, 14, 21 and 28 days. The room $\mathrm{CO}_{2}$ concentration is approximately $530 \mathrm{ppm}$ and inside the chambers there is no air in circulation and no additional $\mathrm{CO}_{2}$ flux. The equilibrium relative humidity (RHeq) of specific supersaturated salt solutions was used to keep the humidity constant at $20^{\circ} \mathrm{C}$ : $\mathrm{MgSO}_{4}(\mathrm{RHeq}$ $90 \%$ ) to simulate a very humid environment, $\mathrm{NaCl}$ (RHeq $75 \%$ ) to simulate a humid environment, $\mathrm{MgNO}_{3}$ (RHeq 54\%) to simulate a dry environment, and $\mathrm{MgCl}_{2}$ ( $\mathrm{RHeq} 33 \%$ ) to simulate a very dry environment.

Additionally, dolostone specimens (less than $10 \%$ of calcite versus dolomite), typically used in historical buildings from Madrid (Spain), have been consolidated with Nanorestore ${ }^{\circledR}$ (as it was previously tested in other research with successfully results ${ }^{27}$ ) at room environmental conditions (40-60\% $\mathrm{RH}$ and $\left.20-25^{\circ} \mathrm{C}\right)$ and studied under Confocal Raman Imaging Spectroscopy to analyze the carbonation of the slaked lime nanoparticles in the pores of the stone at $7,14,21$ and 28 days. 


\subsection{Analytical techniques and experimental procedures}

The calcium hydroxide nanoparticles were analyzed by Transmission Electron Microscopy (TEM), Environmental Scanning Electron Microscopy with Energy Dispersive X-ray Spectroscopy (ESEM-EDS), X-Ray Diffraction analyses (XRD) and Micro Raman Spectroscopy after 7, 14, 21 and 28 days.

Transmission Electron Microscopy (TEM) analyses and their corresponding saedp (selected area electron diffraction patterns) were obtained to distinguish the different mineralogical phases observed at different relative humidities. These analyses were performed to confirm the mineralogical phases identified with the other techniques and to study the shape and the size of the nanoparticles and the structural phases. Samples were prepared by ultrasonic dispersion of this colloidal suspension and then disposed on a carbon coated cupper grid with $3 \mathrm{~mm}$ of diameter. A TEM Jeol JEM operated at $200 \mathrm{KV}$ with electron diffraction mode and Energy Dispersive X-ray Spectroscopy (EDS) Link devices were used for the structural and chemical composition control. Digital Micrograph softwareTM Gatan inc. was used to measure the particle size and for the interpretation of the electron diffraction patterns.

Environmental Scanning Electron Microscopy (ESEM) was performed to study the morphology, size and distribution of the particles disposed on aluminium holders using a Quanta 200 FEI microscope with Energy Dispersive X-ray Spectroscopy (EDS) (model 7509 Oxford Instrument Analytical, UK). Digital Micrograph softwareTM Gatan inc. was used to measuring the size of the particles on the ESEM images.

X-Ray Diffraction analyses (XRD) were performed to determine the mineralogy and crystallinity of the product deposited on metallic siliceous holders. XRD patterns were recorded in an X'Pert Pro MPD Panalytical X'Celerator diffractometer. The sensitivity of this diffractometer allows a faster registration of the XRD patterns and the identification of mineral phases with low crystallinity. The $2 \theta$ range analyzed was $5^{\circ}-80^{\circ}$ with a scan step size of $0.033^{\circ}$ with $200.025 \mathrm{~s} / \mathrm{step}$ in a continuous mode. The working conditions were $45 \mathrm{kV}$ and $40 \mathrm{~mA}$. The mineralogical phases were determined by comparison with the XRD database JCPDS (Joint Committee on Powder Diffraction Standards).

Micro Raman spectroscopy was done to follow the carbonation of the calcium hydroxide nanoparticles. Raman spectra of the product exposed at different $\mathrm{RH}$ and different times were 
taken on $0.5 \pm 0.2 \mathrm{mg}$ of sample disposed on glass slides using a Confocal Raman Microscope Renishaw RM2000 equipped with a 785-nm laser, a Leica microscope and an electrically refrigerated CCD camera. The spectra were obtained with 50x objective lenses. The laser output was $30 \mathrm{~mW}$ and exposure time was 10 seconds. Two software applications, WIRE for Windows and Galactic Industries GRAMS/32TM, were used for data collection and analysis. Five scans were recorded to improve the signal-to-noise ratio. Spectra were taken at 5 different points for each sample to minimize any lack of sample uniformity. The Raman spectra presented are the representative measurements of the five points. The area where vibration modes are found, i.e., $4000-100 \mathrm{~cm}^{-1}$, was the spectral region scanned.

\section{Results and discussion}

\subsection{Calcium hydroxide nanoparticles exposed at $33 \% \mathrm{RH}$}

The main mineralogical phase found in this environment is portlandite. Fig. 1a corresponds to a TEM image in bright field mode and the saedp taken in a sample after 21 days at $33 \% \mathrm{RH}$. Hexagonal portlandite $(P)$ crystals display longer axis ranging between $43.2 \mathrm{~nm}$ and $228 \mathrm{~nm}$.

ESEM images show plate-like $\mathrm{Ca}(\mathrm{OH})_{2}$ nanocrystals that are initially agglomerated and reach particle sizes of $590 \mathrm{~nm} \pm 180 \mathrm{~nm}$ after 28 days (Fig.1b). It is well known that colloids may undergo aggregation and FESEM observations carried out by Rodriguez-Navarro et al., ${ }^{3}$ show the systematic presence of plate-like $\mathrm{Ca}(\mathrm{OH})_{2}$ nanoparticles ranged from $30 \mathrm{~nm}$ up to $200 \mathrm{~nm}$ that aggregate into micron-sized clusters.

Fig.1c shows the results of the XRD data obtained at $33 \% R H$. The XRD patterns after 7 days show that the main peaks are a well defined crystalline phase identified as portlandite $\mathrm{Ca}(\mathrm{OH})_{2}$ (jcpds $=72-0156, a=3.585 \AA, c=4.895 \AA$ ). There is also a presence of a small amount of calcite $\mathrm{CaCO}_{3}(\mathrm{jcpds}=01-0862342, \mathrm{a}=4.989 \AA \mathrm{A}, \mathrm{c}=17.06 \AA$ ). The $\mathrm{XRD}$ data after 28 days reveals a better definition of the intensity maximums associated to calcite phase and a decrease of the portlandite phase. The appearance of monohydrocalcite $\mathrm{CaCO}_{3} \cdot \mathrm{H}_{2} \mathrm{O}$ (jcpds=29-0306, $a=10.56 \AA$, $c=7.573 \AA$ ) was detected in the sample associated to portlandite. A very broad convex shape between $2 \theta=16^{\circ}$ to $28^{\circ}$ can resemble the presence of amorphous hydrated carbonate phase after 7 and 28 days. 
The Raman spectra in the frequencies on the range $200-1200 \mathrm{~cm}^{-1}$ of the calcium hydroxide nanoparticles at $33 \% \mathrm{RH}$ and at different times have been compiled in Fig.1d. The Raman analyses of the product show a signal of $\mathrm{Ca}-\mathrm{O}$ groups from portlandite $\left(\mathrm{Ca}(\mathrm{OH})_{2}\right)$ that is observed at $356 \mathrm{~cm}^{-1}$, and a broad signal with a sharp peak of C-O groups from carbonates that the maximum is observed at $1083 \mathrm{~cm}^{-1}$ indicating the presence of crystalline calcium carbonate and amorphous calcium carbonate ${ }^{10}$.

\subsection{Calcium hydroxide nanoparticles exposed at $54 \%$ RH}

The main mineralogical phase found in this environment is vaterite. Fig. 2a shows a TEM image in bright field mode with the typical habit of the portlandite $(\mathrm{P})$ and vaterite $(\mathrm{V})$ crystals with longer axis between $200 \mathrm{~nm}$ to $1020 \mathrm{~nm}$, after 7 days at 54\% RH. Portlandite appears as idiomorphic and sub-idiomorphic hexagonal tablets ranging between $34 \mathrm{~nm}$ to $113 \mathrm{~nm}$, locally agglomerated forming clusters of $253 \mathrm{~nm}$. Vaterite is usually present as plate-like ${ }^{35}$ or spherulite $^{30}$ crystals. TEM image (Fig. 2a) shows elongated shape vaterite crystals and the saedp (as inset) along the zone axis [-1100] is indexed according to the hexagonal structure.

ESEM images show that plate-like $\mathrm{Ca}(\mathrm{OH})_{2}$ nanocrystals are initially agglomerated, reaching particle sizes of $490 \mathrm{~nm} \pm 100 \mathrm{~nm}$ after 28 days with spherulitic shapes (Fig.2b), although these are lesser agglomerated than those found at $33 \% \mathrm{RH}$.

XRD diffractogram patterns after 7 days at $54 \% \mathrm{RH}$ (Fig.2c) show maximum intensity peaks related to portlandite and vaterite (jcpds $=33-0268, a=7.147 \AA, c=16.91 \AA$ ). Portlandite is common at both $33 \%$ and $54 \% \mathrm{RH}$ environments. However, differences in the relative intensity of the peaks reveal better defined diffraction maximums in the sample exposed at $33 \% \mathrm{RH}$. After 28 days, the diffractograms show a well defined and intense peaks of portlandite and vaterite, the appearance of $\mathrm{CaCO}_{3} \cdot \mathrm{H}_{2} \mathrm{O}$, small peaks of aragonite and there is no presence of calcite. There are more signals of monohydrocalcite on this sample compared to the sample exposed at $33 \% \mathrm{RH}$.

The Raman spectra (Fig.2d) of the sample exposed at $54 \%$ RH show a small Raman band at $356 \mathrm{~cm}^{-1}$ that corresponds to portlandite. This signal is lesser intense than the same signal found in the spectra at $33 \% \mathrm{RH}$ which would mean less proportion of this phase detected at $54 \% \mathrm{RH}$. There is also a broad signal with a sharp peak with the maximum at $1083 \mathrm{~cm}^{-1}$ that indicates the formation of crystalline calcium carbonates (calcite or aragonite) and amorphous 
calcium carbonate. The small broad signal at $701 \mathrm{~cm}^{-1}$ at 28 days could indicate the presence of aragonite. ${ }^{5,36}$ Also at 28 days, the Raman band at $1083 \mathrm{~cm}^{-1}$ shows two small peaks at 1090 $1070 \mathrm{~cm}^{-1}$ from C-O groups that would correspond to vaterite. RS spectra of $\mathrm{CaCO}_{3}$ in aragonite and calcite show a symmetric stretching mode vibration of the carbonate ion presenting a single Raman band at $1085 \mathrm{~cm}^{-1}$, whereas this group produces a vibration that causes a triplet at 1074-1080-1091 $\mathrm{cm}^{-1}$ in vaterite. ${ }^{37}$ Gabrielli et al. ${ }^{38}$ shown through in situ Raman spectroscopy that formation of aragonite on a vaterite crystal is a transformation of the vaterite structure and not a further crystallization of this polymorph upon vaterite crystals. Soldati et al., ${ }^{37}$ studying the structural characterization and chemical composition of aragonite and vaterite in freshwater cultured pearls concluded that both polymorphs must form simultaneously, and vaterite cannot be the precursor of aragonite. Although these and other authors, ${ }^{39,40}$ suggest that the environmental conditions could play a role on the precipitations of these phases. Both phases were also detected under XRD on samples exposed at 54\% RH (Fig.2c) where it can be seen how vaterite is precipitated first, after 7 days, followed by aragonite after 28 days.

\subsection{Calcium hydroxide nanoparticles exposed at $75 \% \mathrm{RH}$}

The main mineralogical phase found in this environment is aragonite. Fig. 3a shows the TEM image and the ring pattern saedp (as inset) of a typical aragonite crystal after 14 days at $75 \%$ $\mathrm{RH}$. Individual prismatic crystals of $54 \mathrm{~nm}$ to $63 \mathrm{~nm}$ are identified giving rise to elongated fibrous aggregated than reach $819 \mathrm{~nm}$.

Under ESEM was possible to observe botroydal shape nanocrystals, often described in the literature ${ }^{10}$ having the form of spherulites and identified as amorphous calcium carbonate hydrated and considered the least stable variety. ${ }^{41}$ This phase gives rise to needle like and spherulitic shape crystals, reaching particle sizes of $260 \mathrm{~nm} \pm 70 \mathrm{~nm}$ at 28 days (Fig.3b). This morphology of crystals is very similar to that identified by Ogino et al., ${ }^{42}$ where vaterite, calcite and small amounts of aragonite were observed as a function of temperature. These authors found that amorphous $\mathrm{CaCO}_{3}$ was initially formed and transformed to a mixture of several crystalline $\mathrm{CaCO}_{3}$ polymorphs that gradually transformed through the dissolution of the metastable phases (vaterite at low temperature or aragonite at high temperature) and growth of the stable phase, calcite. In Fig.3b it can be observed the presence of an amorphous phase which shows signs of dehydration and dissolution and the transformation into other phases. 
Ogino et al., ${ }^{42}$ stated that the transformation from amorphous $\mathrm{CaCO}_{3}$ takes place through the recrystallization of calcium carbonate, and not through a direct solid phase transition, by means of the dissolution of vaterite and the growth of calcite. Tlili et al., ${ }^{11}$ also concluded that, in air and at ambient temperature, the amorphous phase recrystallizes in a few minutes into anhydrous vaterite and calcite, although a slow recrystallization can lead to the monohydrate form.

XRD results show that after 7 days at $75 \% \mathrm{RH}$ (Fig.3c) the sample shows a very broad diffractogram shape with a background hump typical of high content of amorphous phase with diffraction maximum indicating the presence of $\mathrm{CaCO}_{3} \cdot \mathrm{H}_{2} \mathrm{O}$. Associated to monohydrocalcite, vaterite, aragonite (jcpds $=76-0606, \quad a=4.959 \AA, b=7.954 \AA, c=5.737 \AA$ ) and calcite can be identified. After 28 days, continues the presence of monohydrocalcite associated to vaterite, aragonite and calcite, even though the broad diffractogram pattern is still indicating the presence of amorphous calcium carbonate phases.

In the Raman spectra of the sample exposed at $75 \% \mathrm{RH}$ are observed sharp and narrow Raman bands at $1085 \mathrm{~cm}^{-1}$ and $282 \mathrm{~cm}^{-1}$ corresponding to calcite are observed (Fig.3d). This last peak at $282 \mathrm{~cm}^{-1}$ was not observed at lower $\mathrm{RH}$, which would mean and increase in the calcite content at higher HR. There are no portlandite signals at $356 \mathrm{~cm}^{-1}$. There are also Raman bands at $700-704 \mathrm{~cm}^{-1}$ which could corresponds to the presence of aragonite which it is in agreement with the $\mathrm{XRD}$ results (Fig.3c).

\subsection{Calcium hydroxide nanoparticles exposed at $90 \% \mathrm{RH}$}

The main mineralogical phase found in this environment is calcite. Fig .4a displays the TEM image in bright field mode and the saedp (as inset), after 14 days of a calcite crystal with typical rhombohedral shape in a particle of $388 \mathrm{~nm}$ (longer axe) associated to clusters of amorphous calcium carbonate with sizes in the rage $75-497 \mathrm{~nm}$.

ESEM images showed initially botroydal shape nanocrystals that give rise to rhombus (calcite), needle like (aragonite) and spherulitic (vaterite) shape crystals with particle sizes of $2 \square \mathrm{m} \pm 0.5$ $\square \mathrm{m}$ at 28 days (Fig.4b). The same crystal habits were also observed by other authors as Dandeu et al., ${ }^{30}$ Dendrite shaped $\mathrm{CaCO}_{3}$ aggregates observed in Fig. $4 \mathrm{~b}$ consisting of two dendrite-like heads composed of radial aligned crystals could be a mixture of aragonite and calcite. According to Yu et al., ${ }^{43}$ similar crystal shapes obtained under polyvinyl alcohol and high temperature $\left(80^{\circ} \mathrm{C}\right)$ were composed of circa $7 \%$ aragonite and $93 \%$ calcite. By other hand, 
these dendrite-like crystals were identified by Yan et al., ${ }^{23}$ as aragonite crystals. Regarding with vaterite crystals, Nissenbaum et al., ${ }^{44}$ concluded that vaterite particles do not increase in size, but evidence of dissolution increases as calcite particles grow.

The XRD results after 7 days at $90 \% \mathrm{RH}$ display vaterite, monohydrocalcite and strong intensity peaks of calcite. The concave shape of the pattern reveals the presence of some amorphous calcium carbonate. All the phases previously mentioned were also detected after 28 days, with a strong signal around $2 \theta=29^{\circ}$ indicating the presence of calcite, associated to hydrated calcium carbonate, vaterite and aragonite. There is a decrease in the intensity of calcite peaks that could be explained by re accommodations in carbonate polymorphs and in the evidence of the formation of amorphous calcium carbonate and monohydrocalcite. These XRD analyses reveal the fast transformation of portlandite into amorphous calcium carbonate followed by the precipitation of vaterite and aragonite (metastables $\mathrm{CaCO}_{3}$ ) and finally $\mathrm{CaCO}_{3} \cdot \mathrm{H}_{2} \mathrm{O}$ and calcite (stable $\mathrm{CaCO}_{3}$ ). The presence of monohydrocalcite $\mathrm{CaCO}_{3} \cdot \mathrm{H}_{2} \mathrm{O}$ in all the samples at 28 days and also at 7 days at $75 \%$ and $90 \% \mathrm{RH}$ could be explained by the release of $\mathrm{H}_{2} \mathrm{O}$ during the carbonation reaction in the system. The physicochemical processes ${ }^{45,46}$ involved in $\mathrm{Ca}(\mathrm{OH})_{2}$ carbonation are: the diffusion of $\mathrm{CO}_{2}$ in the gaseous phase, the dissolution of $\mathrm{CO}_{2}$ in water as carbonic acid $\mathrm{H}_{2} \mathrm{CO}_{3}$, its dissociation as $\mathrm{HCO}_{3}{ }^{-}$and $\mathrm{CO}_{3}{ }^{2-}$ ions, the dissolution of solid $\mathrm{Ca}(\mathrm{OH})_{2}$, releasing calcium $\mathrm{Ca}^{2+}$ and hydroxyl $\mathrm{OH}^{-}$ions, and the precipitation of $\mathrm{Ca}^{2+}$ with $\mathrm{CO}_{3}{ }^{2-}$ forming $\mathrm{CaCO}_{3}$. These intermediate reactions can be synthesized in the following overall chemical reaction:

$\mathrm{Ca}(\mathrm{OH})_{2}+\mathrm{CO}_{2} \rightarrow \mathrm{CaCO}_{3}+\mathrm{H}_{2} \mathrm{O}$

Vaterite was observed at $54 \%, 75 \%$ and $90 \% \mathrm{RH}$; although it is the most thermodynamically unstable polymorph it is kinetically the most favored of the three polymorphs in terms of crystallization. ${ }^{47}$ Is evident that the growth and the dissolution rate is different for each polymorph, and can be resembled in the differences found in the XRD intensity peaks suggesting the variable molar ratio of vaterite, calcite and aragonite. ${ }^{31}$

In the Raman spectra of the sample exposed at $90 \% \mathrm{RH}$ (Fig.4d) the observed Raman bands are located at $1086 \mathrm{~cm}^{-1}, 710 \mathrm{~cm}^{-1}$ and $280 \mathrm{~cm}^{-1}$, the three of them corresponding to calcite which would mean an increase of this phase in the sample. According to Spanos and Koutsoukos ${ }^{48}$ model, decreasing the relative supersaturation with respect to vaterite increases 
its rate of dissolution whereas the rate of crystallisation of calcite decreases. It is therefore possible in solutions saturated with respect to vaterite the crystallisation rate of calcite becomes predominant. This could partially justify that a higher $\mathrm{RH}$ there is a higher precipitation of calcite compared to the other metastable polymorphic phases.

The calcium hydroxide nanoparticles are dissolved in isopropyl alcohol which could be in part responsible of the stabilization of the metastable calcium carbonate polymorphic phases. According to Manolo and Dalas, ${ }^{49}$ ethanol, isopropanol and diethylene glicol additives influence the morphology of the vaterite crystals formed and stabilize this mineral phase by preventing the transformation to calcite. By other hand, Flaten et al., ${ }^{50}$ indicate that mono ethylene glycol prolongs the transformation time of metastable polymorphs and the effect was shown to be caused by the solvent itself, probably as a result of kinetic stabilization by delaying the growth rate of the more stable polymorphs.

\section{Conclusions}

It has been shown the strong influence of relative humidity on the shape and crystal morphology of calcium hydroxide nanoparticles and on the precipitation and transformation of calcium carbonate polymorphs to consolidate carbonate stones used in cultural heritage.

The combination of TEM-saedp-EDS, ESEM-EDS, XRD and Micro-Raman spectroscopy has been very useful to identify $\mathrm{Ca}(\mathrm{OH})_{2}$ nanoparticles, to follow the carbonation and to distinguish among the different calcium carbonates polymorphs (calcite, aragonite and vaterite) and the hydrated calcium carbonates (amorphous and monohydrocalcite) which precipitation and transformation strongly depends on the relative humidity $(\mathrm{RH})$ : Higher $\mathrm{RH}(75 \%-90 \% \mathrm{RH})$ gives rise to amorphous calcium carbonate and monohydrocalcite, calcite, aragonite and vaterite, faster carbonation and larger particles sizes compared to lower $\mathrm{RH}(33 \%-54 \% \mathrm{RH})$ that gives rise to portlandite and vaterite, slower carbonation and smaller particle sizes.

\section{Acknowledgements.}

This study was funded by the Government of the Community of Madrid under the project "Durability and conservation of traditional natural materials in heritage architecture" (MATERNAS CM 0505/MAT/0094) and the Spanish Ministry of Science and Innovation as part 
of the Consolider-Ingenio 2010 programme (CSD2007-0058). We thank C.T.S. S.R.L for supplying the consolidating product Nanorestore. The authors are grateful to Laura Tormo and Marta Furió of the Natural Science Museum (CSIC) for providing the ESEM photographs and analyses. Special thanks go to Emilio Matesanz from XRD CAI (UCM) for his help with the XRD analyses and Juan Luis Baldonedo from Microscopy Center "Luis Bru" (UCM) for his support with the TEM analyses.

\section{References}

1. J. Ashurst, In: J. Ashurst, Dimes FG (eds), Conservation of Building and Decorative Stone. Butterworth-Heinemann, London (1990).

2. K. Elert, C. Rodríguez-Navarro, E. Sebastián, E. Hansen, O. Cazalla, Stud. Conserv 47(1) (2002) 62-75.

3. C, Rodriguez-Navarro, E, Ruiz-Agudo, M, Ortega-Huertas, E, Hansen, Langmuir 21 (2005) 10948-10957.

4. T. Ogino, T. Suzuki, K.J. Sawada, Cryst Growth 100(1-2) (1990) 159-167.

5. S. Martinez-Ramirez, S. Sanchez-Cortes, J.V. Garcia-Ramos, C. Domingo, C. Fortes, M.T. Blanco-Varela, Cement Concrete Res 33 (2003) 2063-2068.

6. S.S. Potgieter-Vermaak, J.H. Potgieter, R. Van Grieken, Cement Concrete Res 36(4) (2006) 656-662.

7. K.E. Kyung, J. Won, J.J. Kim, Y.S. Kang, S.D. Kim, In: Lukaszewicz JW, Niemcewicz P (eds) Proceedings of the 11th International Congress on Deterioration and Conservation of Stone, Torum, Poland, pp. 915-923 (2008).

8. S. Sequeira, C. Casanova, E.J. Cabrita, J. Cult. Herit 7(4) (2006) 264-272.

9. S.D. Sims, J.M. Didymus, S. Mann, J. Chem. Soc (1995) 1031-1032.

10. R. Clarkson, T.J. Price, C.J. Adams, J.Chem. Soc. Faraday Trans 88 (1992) 243-249.

11. M.M. Tlili, M. Ben Amor, C. Gabrielli, S. Joiret, G. Maurin, P. Rousseau, J. Raman Spectrosc 33 (2001) 10-16.

12. P. Awarwal, K.A. Berglund, Cryst. Growth Des 3(6) (2003) 941-946.

13. L.F. Wang, I. Sondi, E. Matijevic, J. Colloid Interface. Sci 218(2) (1999) 545-553.

14. M. Vucak, J. Peric, M.N. Pons, S. Chanel, Powder Technol 101(1) (1999) 1-6. 
15. E. Altay, T. Shahwan, M. Tanoglu, Powder Technol 178(3) (2007) 194-202.

16. A. Szczes, E. Chibowski, L. Holysz, Colloids Surf A 297(1-3) (2007) 14-18.

17. J. Chen, L. Xiang, Powder Technol 189 (2009) 64-69.

18. J. Baltrusaitis, V.H. Grassian, Surf. Sci 17(1) (2009) 99-104.

19. C.Y. Tai, F.B. Chen, AIChE J 44(8) (1998) 1790-1798.

20. C. Rodríguez-Navarro, C. Jiménez-Lopez, A. Rodríguez-Navarro, M.T. Gonzalez-Muñoz, M. Rodríguez-Gallego, Geochim. Cosmochim Ac 71(5) (2007) 1197-1213.

21. J.G. Carmona, J.G. Morales, R.R. Clemente, J. Colloid Interface Sci 261 (2003) 434-440.

22. H. Wei, Q. Shen, Y. Zhao, Y. Zhou, D. Wang and D. Xu, J. Cryst. Growth 260(3-4) (2004) $511-516$

23. G. Yan, L. Wang, J. Huang, Powder Technol 192(1) (2009) 58-64.

24. R.M. Dheilly, J. Tudo, Y. Sebaı bi, M. Queneudec, Constr. Build. Mater 16 (2002) 155-161.

25. S. Sanchez-Moral, J. Garcia-Guinea, L. Luque, R. Gonzalez-Martin, P. Lopez-Arce, Mater. Construcc 54 (2004) 23-37.

26. A. El-Turki, R.J. Ball, G.C. Allen, Cement Concrete Res 37 (2007) 1233-1240.

27. P López-Arce, L.S. Gomez-Villalba, L. Pinho, M.E. Fernández-Valle, M. Álvarez de Buergo, R. Fort Mater Charact (2009) DOI: 10.1016/j.matchar.2009.11.007.

28. S. Gunasekaran, G. Anbalagan, S. Pandi, J. Raman Spectrosc 37(9) (2006) 892-899.

29. J. Corvisier, A. Fabbri, S. Bernard, F. Brunet, A. Schubnel, B. Goffé, G. Rimmelé, V. BarletGouédard, Geophysical Research Abstracts (2008) 10 EGU2008-A-09511.

30. A. Dandeu, B. Humbert, C. Carteret, H. Muhr, E. Plasari, J.M. Bossoutrot, Chem. Eng. Technol 29(2) (2006) 221-225.

31. C.G. Kontoyannis, N.V. Vagenas, Analyst 125 (2000) 251-255.

32. J. Skibsted, C. Hall, Cement Concrete Res 38(2) (2008) 205-225.

33. Y. Politi, R.A. Metzler, M. Abrecht, B. Gilbert, F.H. Wilt, I. Sagi, L. Addadi, S. Weiner, P.U.P.A, Gilbert. PNAS, 105(45) (2008) 17362-17366.

34. L. Dei, B. Salvadori, J. Cult. Herit 7(2) (2006) 110-115.

35. G. Falini, S.Fermani, S.Vanzo, M. Miletic, G. Zaffino, Eur. J. Inorg. Chem (2005) 162-167.

36. N.V. Vagenas, C.G. Kontoyannis Vib. Spectros 32 (2003) 261-264. 
37. A.L. Soldati, D.E. Jacob, U. Wehrmeister, W. Hofmeister, Mineral.Mag 72(2) (2008) 579592.

38. C. Gabrielli, R. Jaouhari, S. Joiret, G. Maurin, J. Raman Spectrosc 31(6) (2000) 497-501.

39. R.W. Gauldie, J. Morphol 218(1) (1993) 1-28.

40. S. Melancon, B.J. Fryer, S.A. Ludsin, J.E. Gagnon, Z. Yang, Can. J. Fish. Aquat. Sci 62(11) (2005) 2609-2619.

41. L. Brecevic, A.E. Nielsen, J. Cryst Growth 98(3) (1989) 504-510.

42. T. Ogino, T. Suzuki, K. Sawada, Geochim. Cosmochim. Ac 51 (1987) 2757-2767.

43. J. Yu, M. Lei, B. Cheng, X. Zhao, J. Crystal Growth 261(4) (2004) 566-570.

44. J. Nissenbaum, S.L.S. Stipp, A. Johnnson, A Mineral. Mag 72(1) (2008) 473-476.

45. V.A. Juvekar, M.M. Sharma Chem. Eng. Sci 28 (1973) 825-837.

46. M. Thiery, G. Villain, P. Dangla, G. Platret, Cement Concrete Res 37(7) (2007) 1047-1058.

47. S.R. Dickinson, G.E. Henderson, K.M. McGrath, J. Cryst Growth 244 (2002) 369-378.

48. N. Spanos, P. G. Koutsoukos, J. Cryst Growth 191 (1998) 783-790.

49. F. Manoli, E Dalas, J. Cryst Growth 218 (2000) 359-364.

50. E.M Flaten, M. Seiersten, J.P.Andreassen, J. Cryst Growth 311(13) (2009) 3533-3538. 


\section{FIGURE CAPTIONS}

Fig. 1. TEM and saedp (as inset), ESEM, XRD and Micro Raman obtained in the sample of calcium hydroxide nanoparticles at $33 \% \mathrm{RH}$; a) TEM Image in bright field mode and ring pattern saedp of portlandite after 21 days; b) ESEM image after 28 days; c) XRD diffraction pattern after 7 and 28 days; d) Raman spectra after 7, 14 and 28 days.

Fig. 2. TEM and saedp (as inset), ESEM, XRD and Micro Raman obtained in the sample of calcium hydroxide nanoparticles at $54 \% \mathrm{RH}$; a) TEM image of vaterite crystal after 7 days, and the saedp along the zone axis [-1100] indexed according to the hexagonal structure P63/mmm; b) ESEM image after 28 days; c) XRD diffraction pattern after 7 and 28 days; d) Raman spectra after 7,14 and 28 days.

Fig.3. TEM and saedp (as inset), ESEM, XRD and Micro Raman obtained in the sample of calcium hydroxide nanoparticles at $75 \% \mathrm{RH}$; a) TEM image in bright field mode and ring pattern saedp of aragonite after 14 days; b) ESEM image after 28 days; c) XRD diffraction pattern after 7 and 28 days; d) Raman spectra after 7, 14 and 28 days.

Fig.4. TEM and saedp (as inset), ESEM, XRD and Micro Raman obtained in the sample of calcium hydroxide nanoparticles at $90 \% \mathrm{RH}$; a) TEM image in bright field mode and saedp of a calcite crystal after 14 days; b) ESEM image after 28 days; c) XRD diffraction pattern after 7 and 28 days; d) Raman spectra after 7, 14 and 28 days. 


\section{Figure 1}

Click here to download high resolution image
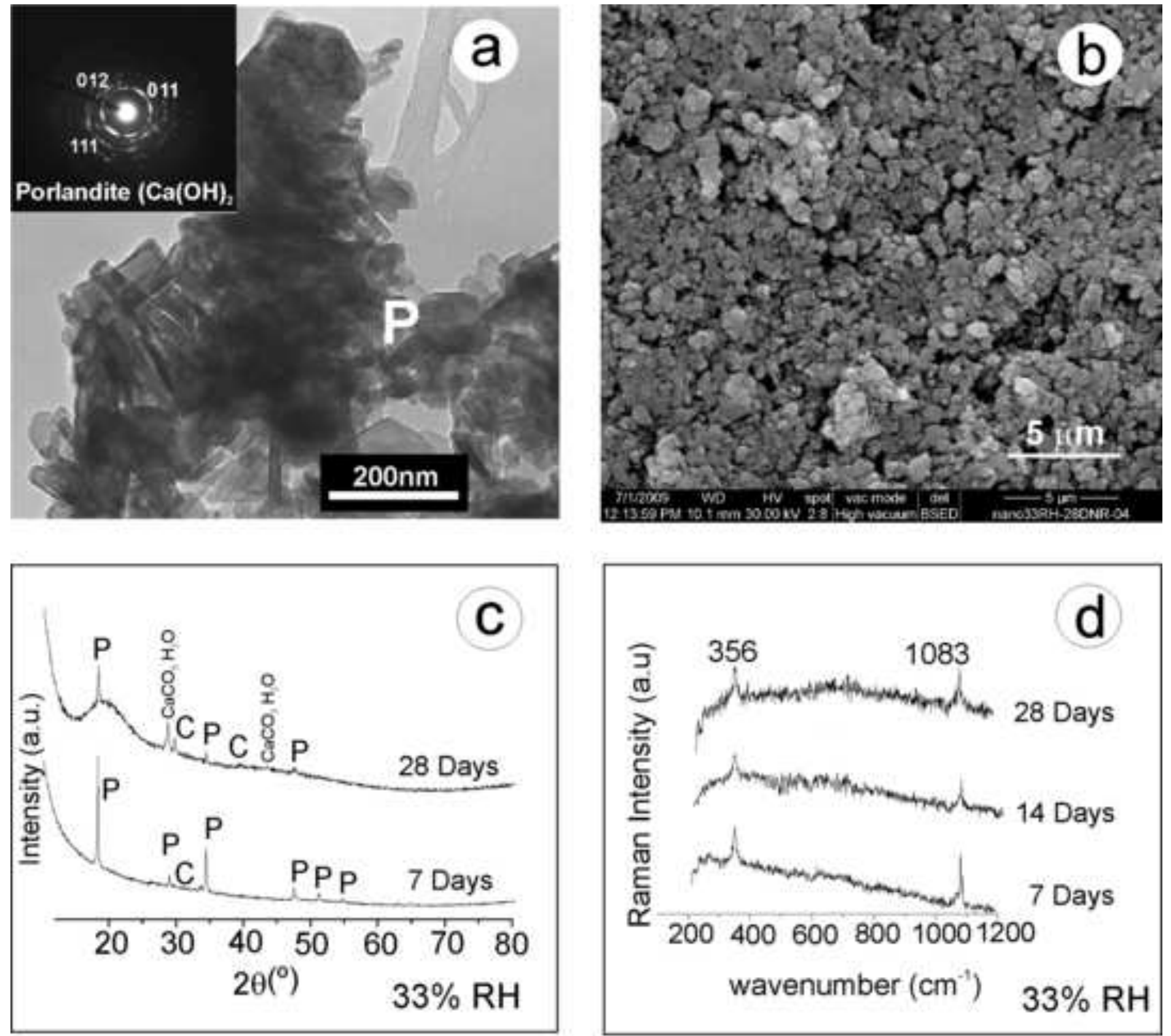

\section{Figure 1}


Click here to download high resolution image
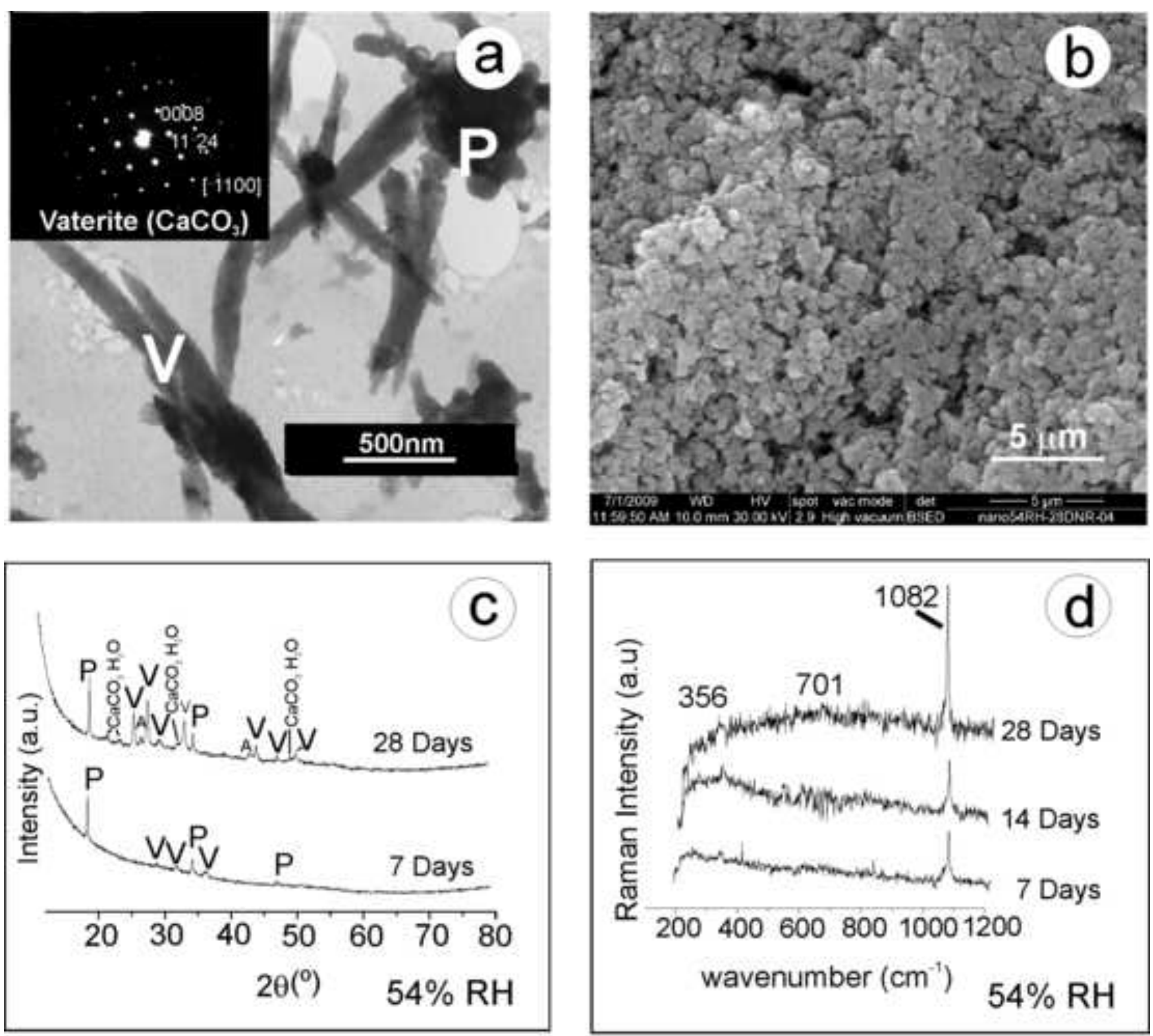

Figure 2 
Click here to download high resolution image
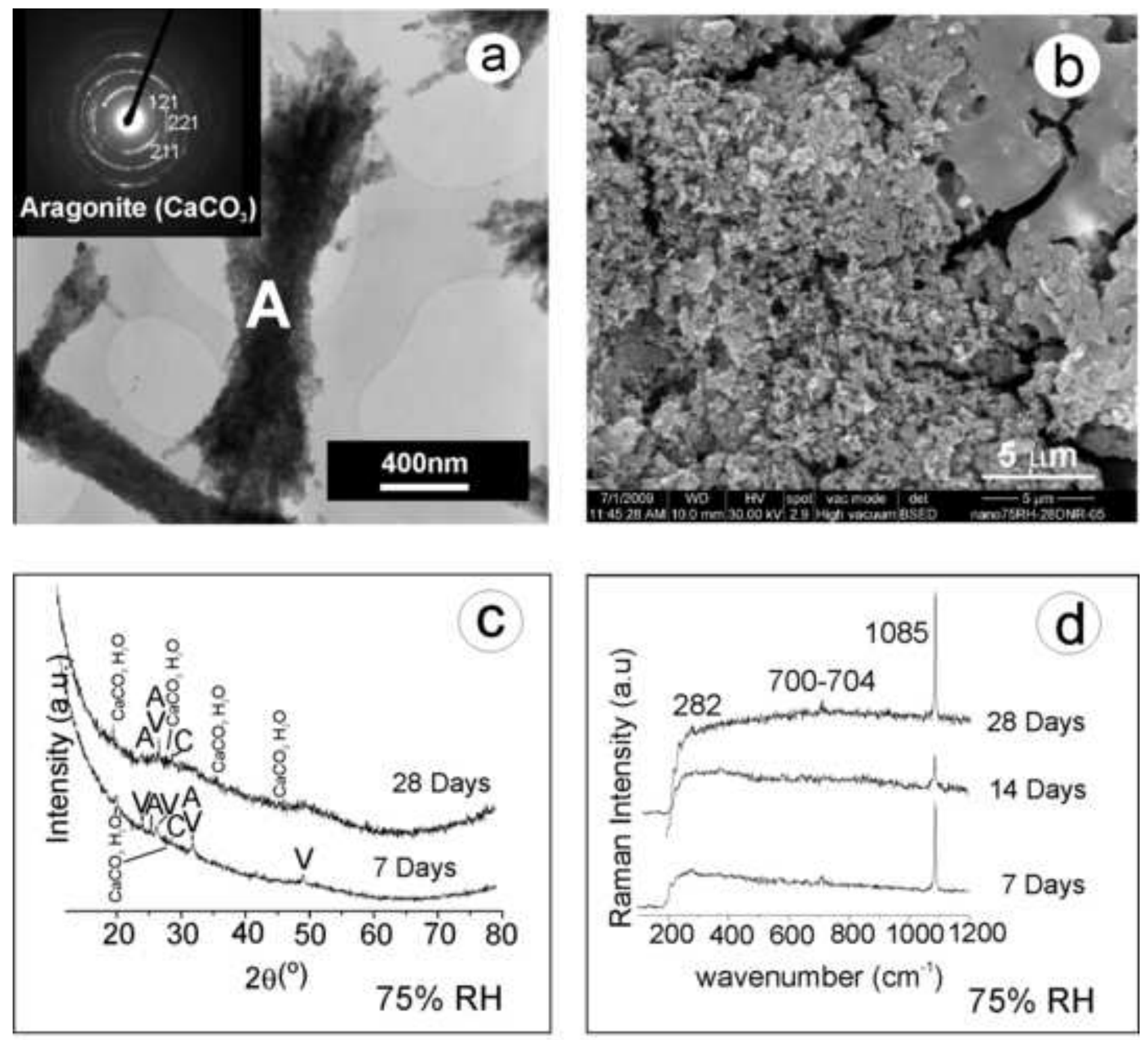

\section{Figure 3}


Click here to download high resolution image
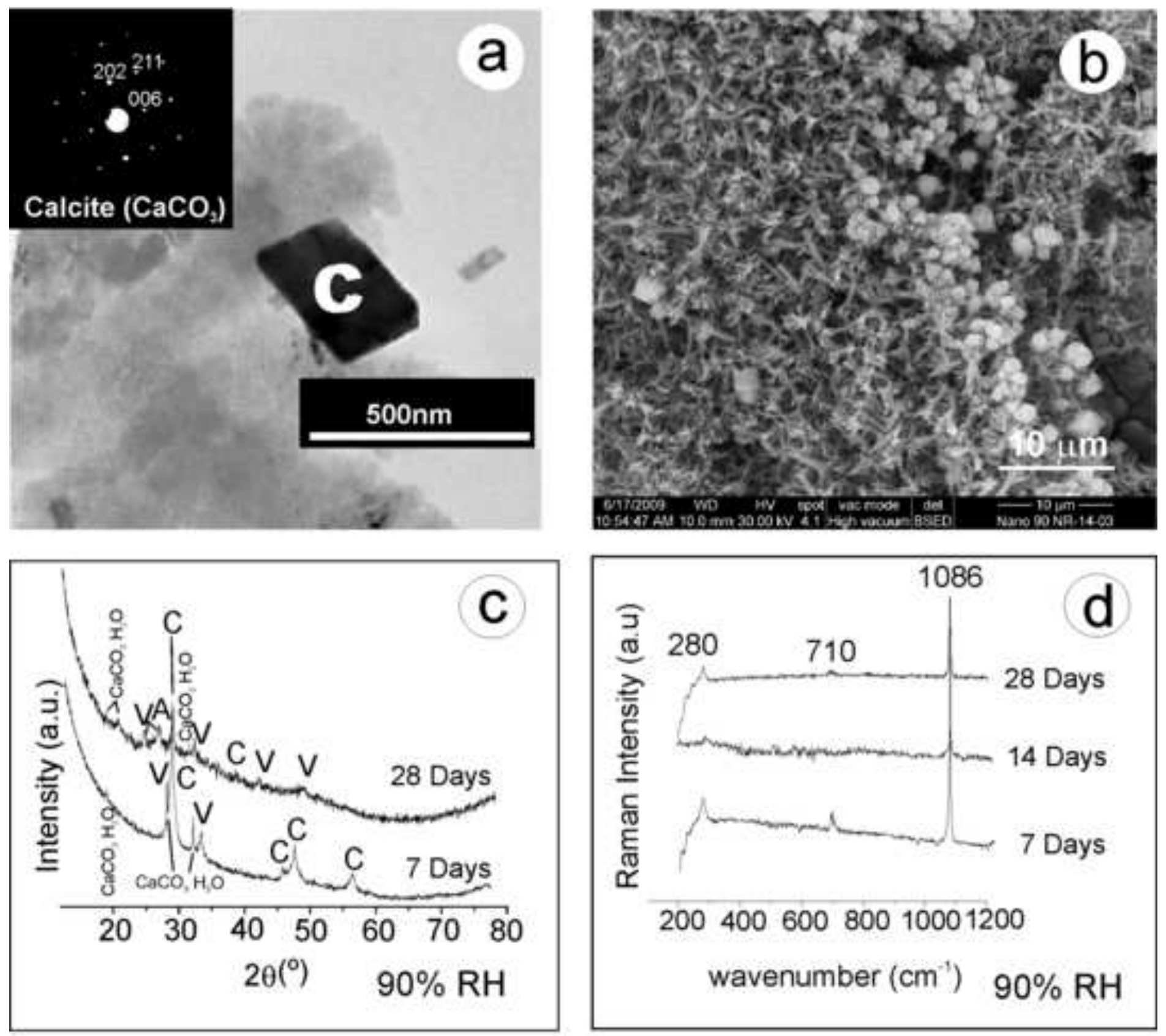

\section{Figure 4}

